\title{
The Influence of Teacher Interaction on the Child School Readiness: Mediation Effect Comparison of Children's Teacher and Institute Preference in Two Groups
}

\author{
Wanjeong Lee \\ Department of Child Psychology, Inha University, Incheon, Korea \\ 교사의 긍정적 상호작용이 취학 전 유아의 학교준비도에 미치는 영향: \\ 저소득층 유아와 일반 유아의 교사 및 기관 선호 매개효과 비교 \\ 이완정 \\ 인하대학교 아동심리학과
}

\begin{abstract}
Objective: The purpose of this study was to examine the influence of teachers' positive interaction on child school readiness which was mediated by child preference for teacher and institute. Further, this study compared the effects between children from low-SES households and children from higher SES households.

Methods: This study used data from the Panel Study on Korean Children and tested two group comparison of the SEM.

Results: The results showed that the teachers' positive interaction affected child school readiness directly and indirectly through children's teacher and institute preference. In addition, teachers' positive interaction on low SES children's preference than comparative group.

Conclusion: The results imply that teachers' positive interaction could be a prevention effect for low SES child adjustment.
\end{abstract}

Keywords: Teacher's Interaction, School Readiness, low-SES Children, Multi Group Analysis, Panel Study on Korean Children

\begin{abstract}
서론
근래 국제협력개발기구(Organization for Economic Cooperation and Development [OECD]) 국가에서는 유아기 경험 박탈을 조 기에 중재하기 위해 유아가 기관에서 양질의 커리큘럼을 경험 하도록 하기 위한 정책적 노력(OECD, 2017)이 지속되어 왔 다. 우리나라에서도 2013년 이후 누리과정 제도를 도입하여

Corresponding Author: Wanjeong Lee, Department of Child Psychology, Inha University, Inharo 100, Nam-gu, Incheon, Korea

E-mail: wanlee@inha.ac.kr
\end{abstract}

전국의 유치원과 어린이집에서 유아에게 양질의 취학 전 커리 큘럼을 시행하도록 지원하고 있다. 누리과정 제도 도입의 주 요 배경 중 하나는 빈곤 가정이나 다문화가정 등 여러 가지 이 유로 유아가 충분한 취학 전 교육경험을 받기 어려울 경우 초 래될 수 있는 학교입학 시 출발선 상의 격차를 해소하기 위한 것(Lee, Choi, Jung, Oh, \& Lee, 2014)이다. Vandell (2004)은 양 질의 조기 중재경험이 발달과정에서 위험요인을 경험한 유아

(C) The Korean Association of Child Studies

This is an Open Access article distributed under the terms of the Creative Commons Attribution Non-Commercial License (http:// creativecommons.org/licenses/by-nc/4.0) which permits unrestricted noncommercial use, distribution, and reproduction in any medium, provided the original work is properly cited. 
의 학교준비도에 상당히 긍정적인 영향을 미쳤다는 연구결과 들을 정리하여 제시하고 있다. 학교준비도는 초기 학습에서 요구되는 기초적인 수준의 지식, 기술 및 태도 등의 획득정도 를 의미하며, 인지 발달이나 언어발달 뿐만 아니라 학습에 대 한 태도나 정서 및 사회능력의 범주까지 포함하고 있다.

학교준비도는 유아의 정서적 능력과 사회적 기술의 토대 위에 형성된 것으로(Ladd, Kochenderfer, \& Coleman, 1996), 진 학 후 1 학년에서의 읽기 및 산수 성적을 예언하는데 중요한 변 인이 되는 것으로 밝혀져 있다(Schaefer \& McDermott, 1999). 일반적으로 학교준비도가 낮은 상태에서 정규 학교 체계에 진 입하는 아동은 책임감 있게 자신의 과제를 수행하지 못하고, 공격적이거나 비사회적인 행동에 가담하며, 중장기적으로는 학교에서 중퇴하거나, 십대에 미혼 부모가 되거나, 성인이 되 어서도 복지나 공적 지원 체계에 의존해서 생활하기 쉬워진다 고 보기 때문에(Shonkoff \& Phillips, 2000), 각국에서는 가능한 조기 중재를 통해 모든 유아의 학교준비도를 높이고자 노력해 왔다.

취학 전 교·보육과정에서 유아의 학교준비도에 효과적인 양질의 커리큘럼 요소가 무엇인가에 대해서는 오랫동안 논쟁 이 있어왔다. Burchinal 등(2008)에 따르면, 양질의 유아기 커 리큘럼에서 가장 중요한 것은 적절한 발달 기대, 통합적인 교 수, 지속적인 평가와 환류, 그리고 민감하고 반응적인 교사 상 호작용이라고 알려져 있다. 특히, 교사의 긍정적 상호작용은 오랫동안 유아기 커리큘럼의 질을 좌우하는 가장 중요한 과정 적 요소로 알려져 왔다(Dickinson, Darrow, \& Tinubu, 2008). 교 사는 유아와의 상호작용 과정에서 유아의 요구를 민감하게 파 악하고 유아의 수준에 따라 적절히 반응하거나, 긍정적인 감 정을 표현하며 유아에게 정서적 지원과 격려를 한다. 교사의 긍정적 상호작용을 통한 정서적 지원은 유아의 발달과 학교준 비도에 긍정적인 영향을 미친다고 밝혀져 왔다. 우리나라의 연구에서도 Kwon과 Lee의 연구(2017)에서 교사의 상호작용은 유아의 사회적 능력과 유의한 관계가 있는 것으로 나타났다. 또한 H. J. Kim과 Kim의 연구(2017)에서 교사 유아 간 긍정적 인 상호작용은 유아의 조망수용 능력과 문제해결 능력에 영향 을 미치는 것으로 나타났다

교사의 긍정적 상호작용이 양질의 유아기 프로그램에서 중요한 요인으로 꼽히기 때문에, $\mathrm{OECD}$ 국가의 정책가들은 특히 빈곤층 유아의 조기 중재를 위한 유아기 프로그램에서 교사의 상호작용을 중시해왔다. Burchinal, Vandergrift, Pianta 와 Mashburn (2010)은 미국 11개주 671개 유아기관에 등록된 1,129 명의 저소득층 유아를 대상으로 교사의 긍정적 상호작
용이 이들의 학교준비도에 중요한 영향을 미치는 변인인지 분 석해보았다. 연구결과, 교사의 긍정적 상호작용은 교사의 명 확한 교수나 지시보다 유아의 학교준비도에 더 큰 영향을 미 치는 것으로 밝혀졌다. 연구에서 유아와의 상호작용이 좋은 교사들은 유아에게 자주 긍정적인 정서표현을 하고, 능동적으 로 유아의 행동을 모니터링하여 유아의 혼란과 갈등을 예방하 였으며, 유아의 요구에 민감하게 응답하여 유아가 학습할 기 회를 많이 조성해주는 것으로 나타났다. 또한 교사들은 유아 와 대화를 많이 하며, 유아의 언어 표현을 이끌어내고, 유아의 생각이나 아이디어, 사고과정을 지원하기 위해 노력하였다.

H. Kim(2015)는 취약한 환경에 처한 저소득층 아동이 가정 에서 경험하기 어려운 긍정적인 정서적 지지나 바람직한 역 할모델을 유아기관이나 학교에서 경험할 경우 이들의 적응 이나 성취에 보다 긍정적인 영향을 받는다고 하였다. 실제 $\mathrm{H}$. $\operatorname{Kim}(2015)$ 의 연구에서 청소년이 학교 환경을 긍정적으로 인 식할 경우 학교적응 유연성이 높아졌는데, 이 효과는 빈곤 청 소년의 경우 비빈곤 청소년보다 1.7 배 이상 높은 것으로 나 타났다. 청소년뿐만 아니라 초등학교 아동의 경우에도 교사 에 대한 긍정적 인식은 이들의 적응을 높여주는 효과가 있다. Burnett (2001)의 연구에서 초등학교 1학년 학생에게 교사가 지속적으로 칭찬을 통한 긍정적 상호작용을 하였을 경우 학생 의 적극적인 피드백이 많아지고 학교적응이 높아지는 것으로 나타났다.

이상의 결과를 종합해 볼 때, 취학 전 유아의 경우에도 교사 로부터 긍정적 상호작용을 경험할 경우 교사 및 기관에 대한 선 호나 애착이 높아질 것으로 추론해볼 수 있다. 교사와 아동 간 관계에 관한 연구경향을 검토한 Sabol과 Pianta (2012)의 고찰에 의하면, 교사와 아동 간 관계의 질이 저소득층 아동의 위험요인 을 중재할 수 있는 것으로 나타났다. Murray와 Greenberg (2000) 는 주변 환경에 대한 초등학교 아동의 인식을 교사와의 관계 및 학교에 대한 유대감으로 측정하고, 이들 변인이 아동의 심리사 회적 적응과 유의한 관계가 있음을 밝혀내었다. 하지만 취학 전 유아가 교사나 학교를 어떻게 인식하고 있는지에 대해서는 연 구가 거의 이루어지지 않아 교사나 기관에 대한 유아의 선호가 어떠한지 살펴볼 필요가 있다. 대상에 대한 유아의 선호는 유 아 자신의 응답보다는 유아의 행동을 관찰하거나, 관찰이 어려 울 경우 유아와 밀접한 관계를 맺고 있는 부모나 교사의 보고 (Bishop, Spence, \& Mcdonald, 2003)로 알아볼 수 있다. 유아나 아동의 취향이나 개인 간 특성의 차이에 대한 교사의 측정은 비 교적 신뢰로우며(Mervielde, Buyst, \& Fruyt, 1995), 내적 일관성 이 있다(Ladd, \& Profilet, 1996)고 알려져 있다. 
결국, 교사의 긍정적 상호작용이 유아의 취학 전 학교준비 도를 높이는 영향 관계에서 유아가 인식하는 교사 및 기관에 대한 선호는 두 변인의 관계를 정적으로 매개할 것이라 예측된 다. 이에 따라 본 연구에서는 취학 전 유아기관의 교사가 나타 내는 긍정적 상호작용이 유아의 교사 및 기관 선호를 높여 이 들의 취학 전 학교준비도에 정적 영향을 미치는 과정을 분석 해보고자 하였다. 또한 변인 간 영향 관계가 저소득층 유아와 일반 유아에게서 다르게 나타나는지 살펴보고자 하였다. 이를 위해 본 연구에서는 한국아동패널조사(Panel Study on Korean Children [PSKC]) 자료를 이용하여 저소득층 유아와 기타 유아 집단을 구분하고 두 집단에서 나타나는 변인 간 관계를 검증해 보고자 하였다. 우리나라의 경우, 2016년부터 국민기초생활 보 장법을 개정하여 이전까지 수급자의 선정이나 급여 지급기준 으로 활용되어온 최저생계비를 '기준 중위소득'으로 개편하여 저소득층 지원정책에 상대적 빈곤 개념을 도입하였다. 이에 따 라 본 연구에서는 중위소득을 기준으로 한 저소득층 집단의 유 아를 일반 유아 집단과 비교하는 집단으로 삼고자 하였다.

누리과정 제도의 시행 목적 중 하나가 양질의 유아기 프로 그램을 도입함으로써 저소득층 유아의 공정한 출발선을 보장 해주는 것에도 불구하고 아직까지 유아기 프로그램의 질적 요
인이 빈곤 유아나 저소득층 유아에게 어떻게 작용하였는지 밝 혀본 연구는 드문 실정이다. 본 연구의 분석 자료인 한국아동 패널조사의 경우, 유아의 교사 및 기관 선호를 조사하고 있으 므로 본 연구에서는 교사의 긍정적인 상호작용이 유아의 교사 및 기관 선호를 높임으로써 유아의 학교준비도에 정적인 영향 을 미치는지의 매개효과를 분석해보고자 하였다. 이상의 논의 를 토대로 도출된 연구문제는 다음과 같다.

\section{연구문제 1}

교사의 상호작용, 유아의 교사 및 기관 선호와 유아의 학교준 비도의 전반적인 경향은 어떠한가?

\section{연구문제 2}

교사의 긍정적 상호작용은 유아의 교사 및 기관 선호를 매개 로 유아의 학교준비도에 영향을 미치는가?

\section{연구문제 3}

교사의 긍정적 상호작용, 유아의 교사 및 기관 선호, 유아의 학교준비도 간 관계는 저소득층 유아와 일반 유아 집단 간에 차이가 있는가?

\section{Table 1}

Participants Backgrounds

\begin{tabular}{|c|c|c|c|}
\hline & Total & Poor group & General group \\
\hline & $N(\%)$ & $N(\%)$ & $N(\%)$ \\
\hline \multicolumn{4}{|l|}{ Gender } \\
\hline Girls & $788(48.6)$ & $52(43.7)$ & $736(49.0)$ \\
\hline Total & $1,620(100.0)$ & $119(100.0)$ & $1,501(100.0)$ \\
\hline Lower than high schools & $437(27.4)$ & $53(48.6)$ & $384(25.8)$ \\
\hline Greater than colleges & $1,159(72.6)$ & $56(51.4)$ & $1,103(74.2)$ \\
\hline Total & $1,620(100.0)$ & $119(100.0)$ & $1,501(100.0)$ \\
\hline \multicolumn{4}{|l|}{ Mothers' Education } \\
\hline Lower than high schools & $473(29.4)$ & $59(50.4)$ & $414(27.7)$ \\
\hline With parents & $1.539(96.9)$ & $105(98.1)$ & $1,434(96.8)$ \\
\hline With only mothers & $45(2.8)$ & $2(1.9)$ & $43(2.9)$ \\
\hline With only gathers & $1(0.1)$ & $0(0.0)$ & $1(0.1)$ \\
\hline Others & $4(0.3)$ & $0(0.0)$ & $4(\quad 0.3)$ \\
\hline Total & $1,620(100.0)$ & $119(100.0)$ & $1,501(100.0)$ \\
\hline
\end{tabular}




\section{연구방법}

\section{연구대상}

본 연구에서는 육아정책연구소(Korea Institute of Childcare and Education [KICCE])의 한국아동패널 2014년 자료를 사용하였 다(KICCE, 2015). 한국아동패널조사는 2008년을 기준을 전국 의 0세 출생아 1,800 여명을 대상으로 실시하였으며, 2014년(7 차년도) 자료는 만 6세에 도달한 유아 1,620명을 대상으로 수 집한 것으로 유아들이 다니는 취학 전 유아기관의 교사에게 유아의 학교준비도 등을 조사한 특성이 있다.

연구대상자를 저소득층 유아와 일반 유아로 구분하기 위 하여 상대빈곤의 구분기준으로 많이 쓰이는 중위소득을 기 준으로 사용하고자 하였다. 이를 위해, 조사년도인 2014년의 전체가구 중위소득 1,966,646원(Korean Statistical Information Service [KOSIS], 2015)을 기준으로 어림하여 월 소득 200만원 까지인 가계의 유아는 저소득층 유아로, 나머지 가계의 유아 는 일반 유아로 구분하였다. 자료 분석 대상자의 일반적 특성 은 Table 1에 제시된 바와 같다.

\section{연구도구}

\section{교사의 긍정적 상호작용: 독립변인}

2014년 조사된 교사의 상호작용은 Holloway와 ReichhartErickson (1988)의 유아관찰도구(Early Childhood Observation Instrument [ECOI])를 한국아동패널 연구진이 일부 수정한 것 을 사용하여 측정되었다. ECOI는 교사-유아 상호작용을 정서 적인 측면에서 살펴볼 수 있는 도구로 알려져 있으며, 이 변인 을 처음 구축한 2011년 자료에서는 교사의 상호작용을 간편 한 문항으로 구성하여 자기 행동에 대한 교사 응답의 객관성 을 높이고자 하였다(KICCE, 2012)고 밝혀져 있다. 교사의 상 호작용 문항은 "아이에게 애정과 신뢰를 가지고 자주 상호작 용한다.”, "아이의 요구를 민감하게 악하고 능동적으로 반응 한다." "아이와 다정하고 자상한 태도로서 대화를 나눈다." 등 총 10 개의 문항으로 구성되어 있다. 각 문항은 교사가 응답하 도록 되어 있으며, 응답은 5점 Likert 척도(전혀 그렇지 않다[1] 매우 그렇다[5])로 점수가 높을수록 교사가 유아와 긍정적 인 상호작용을 하며, 상호작용의 질이 높다는 것을 의미한다. 본 연구에서 교사의 상호작용에 대한 신뢰도 계수(Cronbach's $\alpha)$ 는 .92로 나타났다.

\section{유아의 취학 전 학교준비도: 종속변인}

2014년 조사된 유아의 취학 전 학교준비도는 Murphey와 Burns (2002)의 학교준비도(Ready Kindergartners [RK])를 한국 아동패널 연구진이 번안하여 사용하였다(KICCE, 2015b). 학 교준비도 척도는 사회정서 발달(예: "또래들과 어울릴 수 있 다.”), 학습에 대한 태도(예: “간단한 규칙과 지시를 잘 따른 다.”), 의사소통(예: “욕구, 필요한 것, 생각들을 말로 표현한 다.”), 인지 발달 및 일반적 지식(예: “책의 내용을 이해한다.”) 등의 네 가지 하위 영역 총 22 문항으로 구성되어 있다. 유아가 다니는 기관의 교사가 응답하도록 되어있으며, 4점 Likert척 도(전혀 그렇지 않다[1] 매우 그렇다[4])로 구성되어 있어 점 수가 높을수록 유아의 취학 전 학교준비도가 높다는 것을 의 미한다. 본 연구에서 유아의 학교준비도에 대한 신뢰도 계수 (Cronbach's $\alpha$ )는 .93으로 나타났다.

\section{유아의 교사 및 기관 선호: 매개변인}

2014년 조사된 유아의 교사 및 기관 선호는 한국아동패널조사 연구진이 해외 패널 자료 조사내용의 경향을 토대로 구성한 것 으로 " $\bigcirc \circ$ 이는 같은 학급에 있는 다른 아이들에 비해 귀 기관 을 얼마나 좋아한다고 생각하십니까?”, "○○ 이는 같은 학급에 있는 다른 아이들에 비해 귀하를 얼마나 좋아한다고 생각하십 니까?”의 2문항으로 측정하였다(KICCE, 2015b). 응답은 유아 기관의 교사가 하도록 되어 있으며, 각 문항은 5점 Likert척도 (전혀 그렇지 않다[1] 매우 그렇다[5])로 점수가 높을수록 교 사 및 기관 선호가 높은 것을 의미한다. 본 연구에서 교사 및 기 관 선호에 대한 신뢰도 계수(Cronbach's $\alpha$ )는 .71로 나타났다.

\section{자료 분석}

본 연구에서는 자료 분석을 위해 SPSS 24.0 WIN 프로그램 (IBM Co., Armonk, NY)과 AMOS 24.0 WIN 프로그램(IBM Co., Armonk, NY)을 사용하였다. 측정변인의 평균, 표준편차, 왜도, 첨도 등의 기술통계치로 살펴보고, 신뢰도를 산출하였 다. 또한 변인 간 다중공선성을 파악하기 위해 상관관계 분석 을 하였다. 척도의 구성타당도를 검증하기 위해 확인적 요인 분석을 실시하였다. 변인 간 관계에 대한 구조방정식 모형 분 석을 실시하였는데, 결측치 문제를 해결하기 해 투입된 모든 변수의 정보를 사용하여 결측치를 추정하면서 분석하는 최대 우도법(maximum likelihood)을 사용하였다. 모형의 적합도는 
$\chi^{2}$ 분석, TLI (양호 기준 > .90), NFI (양호 기준 > .90), GFI (양 호 기준 > .90), RMSEA (양호 기준 > .05)을 사용하여 판단하였 다. 매개변인의 효과성 검증은 Sobel Test로 살펴보았다. 마지 막으로, 저소득층 유아와 일반 유아의 집단 간 차이를 살펴보 기 위해 다중집단 분석을 실시하였다. 다중집단 구조모형 분 석은 집단 간 경로계수를 가지고 서로 통계적으로 유의한 차 이가 있는지를 검증하는 것이다.

\section{연구결과}

\section{각 변인의 기술통계치 및 상관분석 결과}

본 연구의 주요 변인에 대한 기술 통계치는 Table 2에 제시된 바와 같다. 교사의 상호작용은 평균 4.26점이며, 표준편차는 .50 이다. 유아의 교사 선호는 평균 4.20점이며, 표준편차는 .56 이고, 유아의 학교준비도는 평균 3.51점, 표준편차는 .40이었 다. 주요 변수들의 정규성을 왜도와 첨도를 기준으로 살펴보
았을 때, 왜도는 절대 값 3 미만, 첨도는 10미만으로 나타나 모 든 변수들이 정규성 가정을 만족하는 것으로 나타났다.

주요 변인에 대하여 저소득층 유아와 일반 유아의 집단 간 차이를 $t$ 검증으로 살펴본 결과, 유아의 학교준비도는 일반 유 아가 평균 3.52점이고 빈곤층 유아는 평균 3.27점으로 집단 간 에 유의한 차이가 있는 것으로 나타났다 $(t=-3.24, p<.001)$. 유 아교사의 상호작용이나 유아의 교사선호에 있어서는 저소득 층 유아와 일반 유아 간 유의한 차이가 나타나지 않았다.

다음으로, 연구모형 분석에 앞서 주요 변수들에 대한 다중 공선성을 검토하기 위해 교사의 상호작용, 유아의 교사 선호, 유아의 학업준비도 간 상관관계를 살펴본 결과가 Table 3에 제시되어 있다. 저소득층 유아나 일반 유아집단 모두 교사의 상호작용과 유아의 교사 선호 간, 유아의 교사선호와 유아의 학교준비도 간, 그리고 교사의 상호작용과 유아의 학교준비도 간에 유의한 정적 상관관계가 있는 것으로 나타났다. 변인 간 상관의 정도는 저소득층 유아가 일반 유아에 비해 높았다. 하 지만, 세 변인 간 상관계수는 모두 .7보다 낮아 다중공선성에 대한 문제는 없는 것으로 나타났다.

Table 2

Descriptive Statistics of Major Variables

\begin{tabular}{|c|c|c|c|c|c|c|}
\hline Variables & Min. & Max. & $M$ & $S D$ & Skewness & Kurtosis \\
\hline Teachers' positive interaction & 2.30 & 5.00 & 4.26 & $(.50)$ & -.40 & -.18 \\
\hline Poor groups & & & 4.21 & $(.55)$ & \multicolumn{2}{|c|}{$t=-.92$} \\
\hline Children's preferences for teacher $\&$ institute & 2.00 & 5.00 & 4.20 & $(.56)$ & -.31 & .04 \\
\hline Poor groups & & & 4.10 & $(.63)$ & \multicolumn{2}{|c|}{$t=-.174$} \\
\hline Poor groups & & & 3.37 & $(.45)$ & \multicolumn{2}{|c|}{$t=-3.24^{* *}$} \\
\hline General groups & & & 3.52 & $(.41)$ & & \\
\hline
\end{tabular}

${ }^{* *} p<0.01$.

Table 3

Correlation Statistics of Major Variables

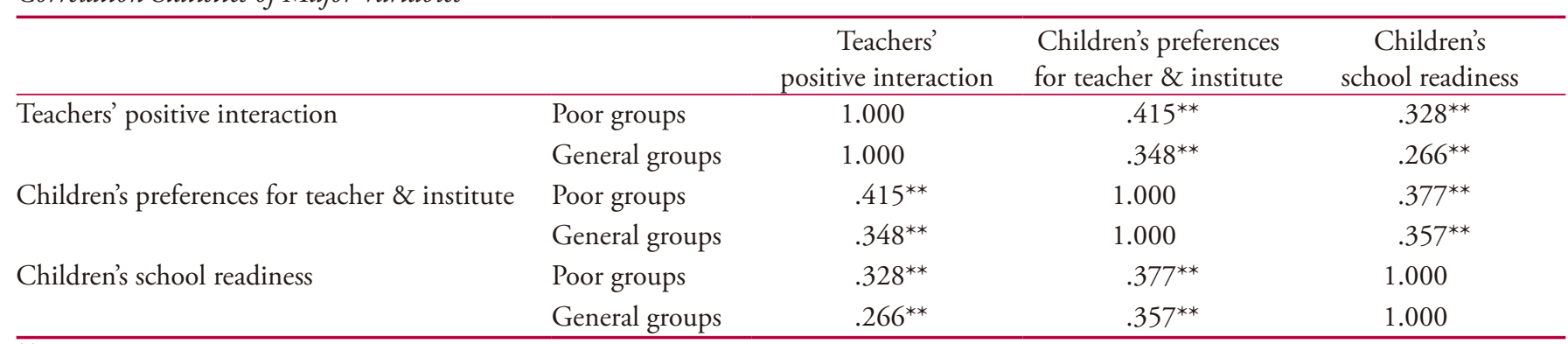

${ }^{* *} p<.01$. 


\section{모형 검증}

\section{측정모형 검증}

본 연구에서 설정한 모형의 측정변수가 잠재변수를 적절하 게 측정하고 있는지 살펴보기 위하여 측정모형을 검증하였다.

그 결과 측정모형의 적합도 지수는 $\chi^{2}=1146.480, d f=104, p<$ $.001, \mathrm{TLI}=.904, \mathrm{CFI}=.916, \mathrm{RMSEA}=.068$ 로 나타나 사례 수 에 민감한 $\chi^{2}$ 를 제외하고는 높은 수준의 적합도를 보였다. 전 체 집단의 잠재변수들 간 공분산 추정치를 살펴본 결과, 교사 의 상호작용과 유아의 교사 선호 간에 상관관계는 $.089(p<$ .001), 유아의 교사 선호와 유아의 학교준비도 간 상관관계는 $.067(p<.001)$, 그리고 교사의 상호작용과 유아의 학교준비도
간 상관관계는 .042 $(p<.001)$ 으로 모두 정적 상관관계를 보 였다. Table 4 에서 보는 바와 같이 16 개의 잠재변수에 대한 요 인부하량은 모두 유의미한 것으로 나타났다.

\section{매개효과 검증}

교사의 상호작용이 유아의 학교준비도에 미치는 영향 관계를 유아의 교사 선호가 매개하는지 살펴보기 위한 구조모형을 검 증하였다. 그 결과 구조모형의 적합도 지수는 $\chi^{2}=626.085, d f$ $=98, p<.001, \mathrm{TLI}=.927, \mathrm{CFI}=.947, \mathrm{RMSEA}=.050$ 으로 나타 나 비교적 양호한 수준의 적합도를 보였다. 전체 집단의 구조 모형에서 나타난 경로계수를 Table 5에서 살펴보면, 교사의 긍정적 상호작용 수준이 높을수록 유아의 학교준비도는 높아

Table 4

Confirmatory Factor Analysis

\begin{tabular}{|c|c|c|c|c|c|}
\hline \multirow[b]{2}{*}{ Latent var. } & \multirow[b]{2}{*}{ Measurement var. } & \multicolumn{2}{|c|}{ Estimate } & \multirow[b]{2}{*}{$S E$} & \multirow[b]{2}{*}{ C.R. } \\
\hline & & $B$ & $\beta$ & & \\
\hline \multirow[t]{7}{*}{ Teachers' positive interaction } & Affection·Trust & $1.000^{* * *}$ & .681 & & \\
\hline & Nice attitudes & $1.020^{* * *}$ & .715 & .045 & 22.462 \\
\hline & Encouragement of independent activities & $1.210^{* * *}$ & .784 & .050 & 24.387 \\
\hline & Free environment & $1.098^{* * *}$ & .716 & .049 & 22.503 \\
\hline & Encouragement of prosocial behavior & $1.060^{* * *}$ & .679 & .050 & 21.412 \\
\hline & Expectations for social behaviors & $1.121^{* * *}$ & .718 & .050 & 22.546 \\
\hline & Support for problem solving & $1.053^{* * *}$ & .693 & .048 & 21.814 \\
\hline \multirow{3}{*}{ Children's school readiness } & Learning attitudes & $1.431^{* * *}$ & .832 & .048 & 29.988 \\
\hline & Communications & $1.429^{* * *}$ & .878 & .045 & 31.546 \\
\hline & Cognition-knowledge & $1.028^{* * *}$ & .750 & .039 & 26.657 \\
\hline
\end{tabular}

${ }^{* * *} p<0.001$.

Table 5

Path Coefficient of Structural Equation Modeling

\begin{tabular}{lrrrr}
\hline \multicolumn{1}{c}{ Path } & $B$ & $\beta$ & $S E$ & C.R. \\
\hline Teachers' positive interaction $\rightarrow$ Children's school readiness & $.089^{* * *}$ & .125 & .025 & 3.557 \\
Teachers' positive interaction $\rightarrow$ Children's preferences for teacher \& institute & $.455^{* * *}$ & .437 & .041 & 11.226 \\
Children's preferences for teacher $\&$ institute $\rightarrow$ Children's school readiness & $.270^{* * *}$ & .398 & .029 & 9.168 \\
\hline
\end{tabular}


Table 6

Direct, Indirect, and Total Effects Predicting School Readiness From Teacher's Interaction and Children's Preferences for Teachers and Institute

\begin{tabular}{|c|c|c|c|}
\hline Path & Total effects & Direct effects & Indirect effects \\
\hline Teachers' positive interaction $\rightarrow$ Children's school readiness & .216 & .090 & .125 \\
\hline Teachers' positive interaction $\rightarrow$ Children's preferences for teacher $\&$ institute & .465 & .465 & \\
\hline Children's preferences for teacher $\&$ institute $\rightarrow$ Children's school readiness & .270 & .270 & \\
\hline
\end{tabular}

Table 7

Results of Sobel Test

\begin{tabular}{lcc}
\hline Path & Indirect effects & Sobel test $(z)$ \\
\hline Teachers' positive interaction $\rightarrow$ Children's preferences for teacher \& institute $\rightarrow$ Children's school readiness & .125 & $7.100^{* * *}$ \\
\hline${ }^{* * *} p<0.001$.
\end{tabular}

*** $p<0.001$.

Table 8

Description of the Models Considered

\begin{tabular}{lcccccc}
\hline & \multicolumn{1}{c}{ 모형 } & $\chi^{2}$ & $d f$ & NFI & CFI & TLI \\
\hline Unconstrained Model & 750.255 & 196 & .927 & .945 & .924 & .042 \\
Model 1 & 778.611 & 209 & .925 & .943 & .926 & .041 \\
Model 2 & 817.073 & 225 & .921 & .941 & .929 & .040 \\
Model 3 & 822.437 & 231 & .920 & .941 & .931 & .040 \\
\hline
\end{tabular}

지는 것으로 나타났다. 또한, 교사의 긍정적 상호작용은 유아 의 교사 선호에 정적인 영향을 주고 있었으며, 유아의 교사 선 호 정도가 높아질수록 유아의 학교준비도 역시 높아지는 것으 로 나타났다.

각 변수 간의 영향관계를 직접효과와 간접효과를 분해하여 살펴본 결과는 Table 6과 같다. 교사의 상호작용은 유아의 교 사 선호에 직접적인 영향 $(\beta=.437)$ 을 미치는 것으로 나타났으 며, 유아의 교사 선호는 유아의 학교준비도에 직접적인 영향 $(\beta=.398)$ 을 미치는 것으로 나타났다. 아울러, 교사의 상호작 용은 유아의 학교준비도에 간접적인 영향 $(\beta=.125)$ 을 미치는 것으로 나타나, 앞서 살펴보았듯이 직, 간접의 영향 모두 유의 한 것으로 나타났다.

본 연구에서는 Sobel test를 이용하여 유아의 교사 선호가 갖는 매개효과를 검증하였다. Table 7에 제시된 바와 같이 $z$ 값 이 7.10으로 산출되어 유의한 Sobel test 값으로 인정되는 1.96 보다 크기 때문에 매개효과가 유의한 것으로 나타났으며, Table 6의 결과와 함께 볼 때, 교사의 긍정적 상호작용이 유아 의 학교준비도에 미치는 영향을 유아의 교사 선호 변인이 부 분 매개하고 있음을 알 수 있다.

\section{저소득층 유아와 일반 유아의 다집단 분석}

본 연구에서는 앞에서 확인한 구조모형에서 잠재변수 간의 경 로가 저소득층 유아와 일반 유아 집단에 따라 유의미한 차이 를 보이는지 확인하기 위하여 구조방정식 모형을 이용한 다중 집단 분석을 실시하였다. 모형 1은 집단 간 요인부하량을 동일 하게 제약한 모델이다. 모형 2 는 집단 간 요인부하량과 공분 산을 동이랗게 제약한 모델이다. 모형 3은 요인부하량, 공분 산, 오차분산을 동일하게 제약한 모델이다. 모형의 비교는 기 저모형과의 적합도 차이를 통하여 살펴본다. $\chi^{2}$ 은 표본크기에 민감하므로 RMSEA나 TLI지수로 모형적합도를 보게 되는데, Table 8과 같이 기저모형의 적합도가 높고 단계별 동일화 제약 을 추가해도 $\chi^{2}$ 을 제외하고는 모형의 적합도 지수들이 거의 나 빠지지 않았으므로 모든 모형에서 차이가 없는 것을 알 수 있 다. 즉, 교차타당도가 검증되어 교사의 상호작용에 따른 유아 의 학교준비도에 대한 척도가 저소득층 유아 집단과 일반 유 아 집단에게서 동일하게 인식되고 있다는 것을 알 수 있다.

본 연구에서 다중집단 구조모형 분석을 통해 저소득층 유 아와 일반 유아 집단의 경로계수를 도출한 결과는 Table 9와 같다. 표를 보면, 저소득층 유아 집단의 경우 교사의 상호작용 
Table 9

Parameter Estimate for Each Group

\begin{tabular}{|c|c|c|c|c|}
\hline \multirow[b]{2}{*}{ Path } & \multicolumn{2}{|c|}{ Poor Groups } & \multicolumn{2}{|c|}{ General Groups } \\
\hline & $B(\beta)$ & C.R. & $B(\beta)$ & C.R. \\
\hline Teachers' Positive Interaction $\rightarrow$ Children's School Readiness & $.081(.127)$ & .98 & $.089(.124)^{* * *}$ & 3.36 \\
\hline Children's Preferences for Teacher $\&$ Institute $\rightarrow$ Children's School Readiness & $.215(.431)^{* *}$ & 2.64 & $.272(.392)^{* * *}$ & 8.72 \\
\hline
\end{tabular}

${ }^{* *} p<0.01 .{ }^{* * *} p<0.001$.

Table 10

Comparison of the Path Difference Between the Low-SES Group and the Comparison Group

\begin{tabular}{lccccc}
\hline \multicolumn{1}{c}{ Models } & $\chi^{2}$ & $d f$ & CFI & TLI & RMSEA \\
\hline Unconstrained Model & 778.611 & 209 & .943 & .926 & .041 \\
Path Constrained Model & 778.766 & 212 & .944 & .928 & .041 \\
\hline
\end{tabular}
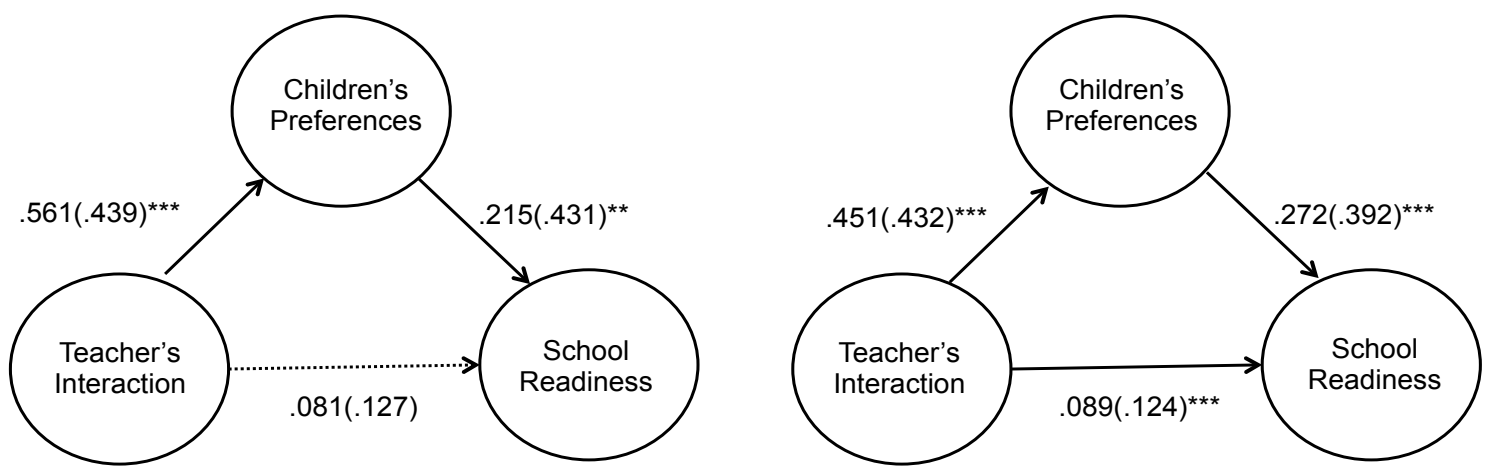

Figure 1. Structural equation modeling of the Low-SES group and the comparison group. Non-standardized (standardized) coefficients are given.

${ }^{* *} p<0.01 .{ }^{* * *} p<0.001$.

이 유아의 학교준비도에 미치는 직접적인 영향은 유의하지 않 은 것으로 나타났다. 대신, 교사의 상호작용은 유아의 교사 선 호를 매개로 유아의 학교준비도에 간접적인 영향을 미치는 완 전매개 효과를 나타내었다.

이와 비교하여, 일반 유아 집단에서는 교사의 상호작용이 유아의 학교준비도에 직접적인 영향을 미치고 있을 뿐 아니 라, 유아의 교사 선호를 매개로 간접적인 영향도 미치는 부분 매개 효과가 있는 것으로 나타났다.

마지막으로, 저소득층 유아와 일반 유아 집단의 두 구조모 형에서 잠재변수 간 인과관계가 양 집단 간에 유의한 차이를 보이지는 않는지 검증하였다. 이를 위해 모형 내 존재하는 경 로계수들에 각각 동일성 제약을 가한 경로제약모형을 기저모 형과 비교하여 그 결과를 Table 10에 제시하였다. 표에 나타난 바와 같이, 각 경로에 동일하게 제약을 가해도 기저모형과 비
교하여 적합도 수치에는 거의 차이가 나타나지 않는다. 이 결 과로 미루어 볼 때, 경로계수들 간의 구조적 관계는 저소득층 유아 집단과 일반 유아 집단 모두에 동등하게 적용될 수 있음 을 알수 있다.

이상의 결과를 종합하여, 저소득층 유아와 일반 유아 집단 에서 나타난 최종 구조모형의 경로계수 추정치를 Figure 1과 같이 나타낼 수 있다. 두 집단에서, 교사의 상호작용이 유아의 교사 선호에 미치는 영향은 일반 유아 집단 $(B=.432, p<.001)$ 보다는 저소득층 유아 집단 $(B=.439, p<.001)$ 에서 더 강하게 작용하고 있었다. 저소득층 유아 집단의 경우, 교사의 긍정적 상호작용이 높을수록 유아의 교사 선호가 높아지고, 이를 매 개로 유아의 학교준비도가 높아지는 완전매개 효과가 나타났 다. 이와 비교하여, 일반 유아 집단에서는 교사의 상호작용이 유아의 학교준비도에 직접적인 영향을 미칠 뿐 아니라 유아의 
교사 선호를 매개로 간접적인 영향도 미치는 부분매개 효과가 나타나 저소득층 유아 집단과 다른 경향을 보였다.

\section{논의 및 결론}

본 연구에서는 교사의 상호작용, 유아의 교사 및 기관 선호, 유 아의 학교준비도의 전반적 경향을 살펴보고, 교사의 상호작용 이 유아의 학교준비도에 미치는 영향의 관계에서 유아의 교사 및 기관 선호가 매개효과를 갖는지 확인하기 위하여 변인들 간의 관계를 설정한 구조모형을 검증해보았다. 이를 위해 측 정모형의 적합도를 살펴본 후 구조모형의 적합도와 각 경로에 서의 유의성을 검증하고, 구조모형의 경로에서 저소득층 유아 와 일반 유아 간에 집단 간 차이가 있는지 살펴보았다. 이 연구 에서 나타난 주요 결과는 다음과 같다.

첫째, 교사의 긍정적 상호작용은 집단 평균이 매우 높은 편 이었고, 유아의 교사 및 기관 선호나 학교준비도 역시 평균값 이 상당히 높은 편이었다. 그럼에도 불구하고, 유아의 학교준 비도의 경우 저소득층 유아 집단이 일반 유아에 비해 유의하 게 낮은 것으로 나타났다. 이러한 결과는 누리과정의 효과 분 석에서 다문화가족, 기초생활보장 수급 가정, 한 부모 가족 등 취약계층 에 속한 유아의 평균 점수가 그렇지 않은 유아에 비 해 전반적으로 낮은 것으로 나타난 Lee 등(2014)의 분석 경향 과 유사한 것이다. 하지만, Lee 등(2014)의 연구에서 집단 간 차이는 통계적으로 유의하지는 않았으며, 취약집단의 표본 수 가 매우 적었으므로 일반화시키기는 어렵다는 한계가 있다. 본 연구에서 저소득층 유아의 학교준비도가 일반 유아에 비해 낮게 나타난 결과는 저소득층 유아를 대상으로 한 중재노력이 정책적으로 보다 체계화될 필요가 있음을 시사한다.

둘째, 교사의 긍정적 상호작용이 높을수록 유아의 학교 준비도가 높아지는 것으로 나타났다. 이러한 결과는 교사의 상호작용과 유아의 학교준비도간 관계를 살펴본 선행연구 (Burchinal et al, 2008; May et al, 1994)를 지지하는 결과이다. 또 한 본 연구의 결과는 유아기 커리큘럼의 질적 요인 중 교사의 긍정적 상호작용이 유아의 발달 및 적응에 중요한 변인이라는 주장(Vandell, 2004)과도 일관된 것이라 할 수 있다.

셋째, 유아의 교사 및 기관 선호가 교사의 긍정적 상호작 용과 유아의 학교준비도 간 관계를 매개하는 것으로 나타났 다. 교사의 긍정적 상호작용이 유아의 교사 및 기관 선호를 높이는 본 연구의 결과는 교사가 유아의 상호작용 과정에서 유아의 요구에 민감하게 반응하고, 유아와 풍부한 언어교환
을 하며, 유아의 흥미와 문제에 같이 공감하고 지원해주는 것 이 유아의 교사 애착을 증진시킨다는 Pianta, Nimetz와 Bennett (1997)의 연구를 지지한다. 또한 이는 교사와 아동 간 관계의 질이 아동의 학습능력을 예측해준다는 Sabol과 Pianta (2012) 의 교사-아동 간 애착 이론모형을 지지해주는 것이기도 하다. 유아기 때 교사와 긍정적인 관계를 형성하는 유아의 능력이 초등학교 진학 후 새로운 교사와 긍정적 관계를 형성하는 능 력으로 이어진다는 Howes, Phillipsen와 Peisner-Feinberg (2000) 의 연구결과를 고려할 때, 교사가 유아와 긍정적인 상호작용 을 많이 할수록 유아가 교사 및 기관을 선호하는 정도가 높아 진다고 밝혀진 본 연구의 결과는 유아의 장기적인 학교적응에 있어 유아의 교사 및 기관 선호가 유의한 정서적 매개변인으 로 작용될 수 있음을 시사한다.

셋째, 저소득층 유아 집단의 경우 유아의 교사 및 기관 선 호가 교사의 긍정적 상호작용과 유아의 학교준비도간 관계를 완전 매개하는 것으로 나타났고, 이와 비교하여 일반 유아 집 단의 경우 유아의 교사 및 기관 선호가 두 변인 간 관계를 부 분 매개하는 것으로 나타났다. 또한 저소득층 유아 집단의 경 우 일반 유아에 비해 교사의 긍정적 상호작용이 유아의 교사 및 기관 선호에 미치는 영향력이 큰 것으로 나타났다. 이러한 결과는 교사의 긍정적 상호작용이 저소득층 아동의 발달 궤 적에 전환을 불러올 수 있는 강력한 보호요인으로 작용한다 는 Luthar, Cicchetti와 Becker (2000)의 주장을 뒷받침해주는 것 이라 할 수 있다. 또한 본 연구의 결과는 외현화된 행동문제를 겪는 아동이 교사와의 관계에서 어려움을 겪을 수 있지만, 유 아기나 초등학교에서 교사로부터 지지적인 지원을 받는다면 이를 극복해낼 수 있다는 선행연구의 결과들(Hamre \& Pianta, 2005; Meehan, Hughes, \& Cavell, 2003)과 일관된 것이기도 하 다. 하지만, 일반 유아 집단에서 교사의 긍정적 상호작용이 유 아의 학교준비도에 직접적 영향을 미친 것으로 나타난 결과와 비교해볼 때, 저소득층 유아 집단의 경우 학교준비도가 높아 지기 위해서는 교사의 긍정적 상호작용뿐만 아니라 이것에 의 해 촉발된 유아의 교사 선호 및 기관 선호가 있어야 한다는 결 과는 저소득층 유아의 학교준비도를 위해서는 보다 많은 중재 노력이 있어야 함을 시사한다고도 할 수 있다.

본 연구를 통하여 유아기관 교사의 긍정적 상호작용이 취 학 전 유아의 교사 및 기관 선호를 높임으로써 유아의 학교준 비도에 정적인 영향을 미치며, 이러한 관계는 특히 저소득층 유아 집단에서 보다 강하게 나타난다는 것이 밝혀졌다. 본 연 구의 결과는 교사의 긍정적 상호작용이 유아기 커리큘럼의 질 적 수준을 나타내는 중요한 지표라는 Vandell (2004)의 종합적 
인 주장과 교사의 상호작용이 유아와 교사 간 애착 관계를 증 진시킨다는 Sabol과 Pianta (2012)의 이론을 대체로 지지한다. 또한 교사가 유아의 요구에 민감하게 반응하고, 유아와 풍부 한 의사소통을 하며, 유아의 관심과 문제에 지원적인 태도를 보일 경우 이는 교사와 유아 간 관계를 증진시킴으로서 저소 득층 유아의 위험요소를 중재해줄 수 있다는 선행연구의 결과 (Luthar et al., 2000)를 실증적으로 확인시켜 준다.

이러한 결론을 토대로 후속연구를 위한 제언을 하면 다음 과 같다. 첫째, 본 연구에서는 유아의 교사 및 기관 선호를 두 문항으로만 살펴보았으며 이를 교사의 응답으로 측정하였다 는 한계가 있다. 추후 연구에서는 유아-교사 간 관계를 보다 많은 변인으로 측정할 필요가 있으며 유아의 선호를 유아의 행동으로 관찰하여 측정하는 등 조사방법의 다변화가 필요할 것이다. 둘째, 본 연구에서는 교사의 긍정적 상호작용을 교사 자신의 응답으로 측정하였다는 한계가 있다. 교사의 상호작용 은 유아의 적응에 매우 중요하다고 알려진 변인이므로 직접 관찰을 통한 측정이 보다 신뢰로울 수 있다. 추후 연구에서는 교사의 상호작용을 외부자의 직접 관찰이나 비디오 관찰 등의 방법으로 보완할 필요가 있을 것이다. 셋째, 본 연구에서는 중 위소득을 기준으로 어림하여 저소득층 유아 집단을 분류하였 다. 향후 연구에서는 상대빈곤을 기준으로 빈곤 유아 집단을 규명하거나 일상에서 경험하는 빈곤의 내용을 다면적으로 살 펴보는 복합지표를 사용하여 빈곤 유아 집단을 규명함으로써 빈곤 유아의 취학 전 기관 경험이 이들의 학교준비도에 어떤 영향을 미치는지, 그리고 이 과정에서의 보호요인은 무엇인지 에 대해 보다 체계적으로 살펴볼 필요가 있다. 이러한 제한점 에도 불구하고 본 연구는 취학 전 유아를 대상으로 교사의 긍 정적 상호작용이 학교준비도에 영향을 미친다는 점과 유아의 교사 및 기관 선호가 두 변인 간 관계를 매개한다는 점을 실증 해보았다는 의의를 갖는다.

\section{Acknowledgements}

This work was supported by INHA UNIVERSITY Research Grant.

\section{Notes}

This article was presented as a poster at the 2017 Annual Fall Conference of the Korean Association of Child Studies.

\section{Conflict of Interest}

No potential conflict of interest relevant to this article was reported.

\section{References}

\section{In English}

Bishop, G., Spence, S. H., \& Mcdonald, C. (2003). Can parents and teachers provide a reliable and valid report of behavioral inhibition? Child Development, 74(6), 1899-1917. doi:10.1046/ j.1467-8624.2003.00645.x

Burchinal, M., Howes, C., Pianta, R., Bryant, D., Early, D., Clifford, R., \& Barbarin, O. (2008). Predicting child outcomes at the end of kindergarten from the quality of pre-kindergarten teacher-child interactions and instruction. Applied Developmental Science, 12(3), 140-153. doi:10.1080/10888690802199418

Burchinal, M., Vandergrift, N., Pianta, R., \& Mashburn, A. (2010). Threshold analysis of association between child care quality and child outcomes for low-income children in prekindergarten programs. Early Childhood Research Quarterly, 25(2), 166-176. doi:10.1016/j.ecresq.2009.10.004

Burnett, P. C. (2001). Elementary students' preferences for teacher praise. The Journal of Classroom Interaction, 36(1), 16-23. Retrieved from http://www.jstor.org/stable/23870540

Dickinson, D. K., Darrow, C. L., \& Tinubu, T. A. (2008). Patterns of teacher-child conversations in Head Start classrooms: Implications for an empirically grounded approach to professional development. Early Education and Development, 19(3), 396-429. doi:10.1080/10409280802065403

Hamre, B. K., \& Pianta, R. C. (2005). Can instructional and emotional support in the first-grade classroom make a difference for children at risk of school failure? Child Development, 76(5), 949-967. doi:10.1111/j.14678624.2005.00889.x

Holloway, S. D., \& Reichhart-Erickson, M. (1988). The relationship of day care quality to children's free-play behavior and social problem-solving skills. Early Childhood Research Quarterly, 3(1), 39-53. doi:10.1016/0885-2006(88)90028-2

Howes, C., Phillipsen, L. C., \& Peisner-Feinberg, E. (2000). The consistency of perceived teacher-child relationships between preschool and kindergarten. Journal of School Psychology, 38(2), 113-132. doi:10.1016/S0022-4405(99)00044-8

Ladd, G. W., \& Profilet, S. M. (1996). The child behavior scale: A teacher-report measure of young children's aggressive, 
withdrawn, and prosocial behaviors. Developmental Psychology, 32(6), 1008-1024. doi:10.1037/0012-1649.32.6.1008

Ladd, G. W., Kochenderfer, B. J., \& Coleman, C. C. (1996). Friendship quality as a predictor of young children's early school adjustment. Child Development, 67(3), 1103-1118. doi: $10.2307 / 1131882$

Luthar, S. S., Cicchetti, D., \& Becker, B. (2000). The construct of resilience: A critical evaluation and guidelines for future work. Child Development, 71(3), 543-562. doi:10.1111/14678624.00164

May, D., Kundert, D., Nikoloff, O., Welch, E., Garrett, M., \& Brent, D. (1994). School readiness: An obstacle to intervention and inclusion. Journal of Early Intervention, 18(3), 290-301. doi:10.1177/105381519401800304

Meehan, B. T., Hughes J. N., \& Cavell T. A. (2003). Teacherstudent relationships as compensatory resources for aggressive children. Child Development, 74(4), 1145-1157. doi:10.1111/1467-8624.00598

Mervielde, I. Buyst, V., \& Fruyt, F. D. (1995). The validity of the Big-Five as a model for teachers' ratings of individual differences among children aged 4-12 years. Personality and Individual Differences, 18(4), 525-534. doi:10.1016/01918869(94)00175-R

Murphey, D. A., \& Burns, C., E. (2002). Development of a Comprehensive Community Assessment of School Readiness. Early Childhood Research and Practice, 4(2), Retrieved from http://ecrp.illinois.edu/v4n2/murphey.html

Murray, C., \& Greenberg, M. T. (2000). Children's relationship with teachers and bonds with school an investigation of patterns and correlates in middle childhood. Journal of School Psychology, 38(5), 423-445. doi:10.1016/S00224405(00)00034-0

OECD. (2017). Starting strong IV: Monitoring Quality in Early Childhood Education and Care. Paris: OECD Publishing. doi:10.1787/9789264233515-en

Pianta, R. C., Nimetz, S. L., \& Bennett, E. (1997). Motherchild relationships, teacher-child relationships, and school outcomes in preschool and kindergarten. Early Childhood Research Quarterly, 12(3), 263-280. doi:10.1016/S08852006(97)90003-X

Sabol, T. J., \& Pianta, R. C. (2012). Recent trends in research on teacher-child relationships. Attachment \& Human Development, 14(3), 213-231. doi:10.1080/14616734.201 2.672262

Schaefer, B. A., \& McDermott, P. A. (1999). Learning behavior and intelligence as explanations for children's scholastic achievement. Journal of School Psychology, 37(3), 299-313. doi:10.1016/S0022-4405(99)00007-2

Shonkoff, J. P., \& Phillips, D. A. (Eds.). (2000). From neurons to neighborhoods: The science of early childhood development. Washington: National Academy Press.

Vandell, D. L. (2004). Early child care: The known and the unknown. Merrill-Palmer Quarterly, 50(3), 387-414. doi:10.1353/mpq.2004.0027

\section{In Korean}

Kim, H. (2015). The effects of perceived school environment on school resilience: A comparison between poor and nonpoor adolescents. Studies on Korean Youth, 26(1), 269-291. doi:10.14816/sky.2015.26.1.269

Kim, H. J., \& Kim, E. K. (2017). Associations between teacherchild interactions and children's perspective-taking and interpersonal problem-solving abilities. Journal of Educational Studies, 48(2), 1-19.

Korea Institute of Childcare and Education. (2012). Instrument profile for Panel Study of Korean Children 4th survey. Retrieved from http://panel.kicce.re.kr/

Korea Institute of Childcare and Education. (2015a). Panel Study of Korean Children 7th survey [Data file and code book]. Retrieved from http://panel.kicce.re.kr/

Korea Institute of Childcare and Education. (2015b). Instrument profile for Panel Study of Korean Children 7th survey. Retrieved from http://panel.kicce.re.kr/

Korean Statistical Information Service. (2015). Kagyedonghyangjosa: 2014 Sodeukbunbaejipyo [가계동향조사: 2014 년 소득분배지표]. Retrieved from KOSIS website: http:// kosis.kr/

Kwon, Y., \& Lee, S. (2017). Effect of teacher efficacy and teacher child interactions on the child's social skills. The Journal of Child Education, 26(2), 115-129. doi:10.17643/KJCE.2017.26.2.06

Lee, J., Choi, H., Jung, Y., Oh, U. J., \& Lee J. (2014). An analysis on the effect of Nuri Curriculum for age 3-5 using the development of the child assessment scale(Report No. 201427). Seoul: Korea Institute of Child Care and Education. Retrieved from KICCE website: http://www.kicce.re.kr/kor

\section{ORCID}

Wanjeong Lee http://orcid.org/0000-0002-2000-2279

Received November 5, 2017 Revision received December 5, 2017 Accepted December 6, 2017 
